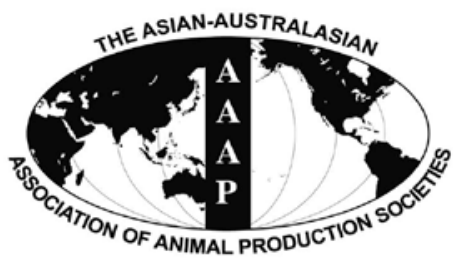

Asian-Aust. J. Anim. Sci.

Vol. 25, No. $1: 1$ - 16

January 2012

www.ajas.info

http://dx.doi.org/10.5713/ajas.2011.r.08

\title{
Roles of Conceptus Secretory Proteins in Establishment and Maintenance of Pregnancy in Ruminants
}

\author{
Fuller W. Bazer ${ }^{1,2, *}$, Gwonhwa Song ${ }^{2}$ and William W. Thatcher ${ }^{3}$ \\ ${ }^{1}$ Department of Animal Science and Center for Animal Biotechnology and Genomics, Texas A\&M University, \\ College Station, Texas 77843-2471, USA
}

\begin{abstract}
Reproduction in ruminant species is a highly complex biological process requiring a dialogue between the developing conceptus (embryo-fetus and associated placental membranes) and maternal uterus which must be established during the periimplantation period for pregnancy recognition signaling and regulation of gene expression by uterine epithelial and stromal cells. The uterus provide a microenvironment in which molecules secreted by uterine epithelia and transported into the uterine lumen represent histotroph, also known as the secretome, that are required for growth and development of the conceptus and receptivity of the uterus to implantation by the elongating conceptus. Pregnancy recognition signaling as related to sustaining the functional lifespan of the corpora lutea, is required to sustain the functional life-span of corpora lutea for production of progesterone which is essential for uterine functions supportive of implantation and placentation required for successful outcomes of pregnancy. It is within the peri-implantation period that most embryonic deaths occur in ruminants due to deficiencies attributed to uterine functions or failure of the conceptus to develop appropriately, signal pregnancy recognition and/or undergo implantation and placentation. The endocrine status of the pregnant ruminant and her nutritional status are critical for successful establishment and maintenance of pregnancy. The challenge is to understand the complexity of key mechanisms that are characteristic of successful reproduction in humans and animals and to use that knowledge to enhance fertility and reproductive health of ruminant species in livestock enterprises. (Key Words : Uterus, Interferon Tau, Pregnancy, Nutrition, Implantation, Gene Expression)
\end{abstract}

\section{INTRODUCTION}

This review describes development of the periimplantation conceptus (embryo/fetus and associated extraembryonic membranes), events associated with implantation and pregnancy recognition signals from the conceptus to the maternal system in ruminants. Pregnancy is established and maintained in response to interactions among the conceptus, ovary and uterus. This biochemical dialogue occurs throughout pregnancy, and the first critical process for pregnancy recognition involves paracrine regulation of the uterine endometrium by the conceptus to abrogate the mechanism responsible for pulsatile release of luteolytic prostaglandin $F_{2 \alpha}$ (PGF). The antiluteolytic

\footnotetext{
* Corresponding Author : Fuller W. Bazer. Tel: +1-979-862-2659, Fax: +1-979-862-2662, E-mail: fbazer@cvm.tamu.edu

2 WCU Biomodulation Major, Department of Agricultural Biotechnology, Seoul National University, 599 Gwanak-ro, Gwanak-gu, Seoul 151-921, Korea.

3 Department of Animal Sciences, University of Florida, Gainesville, Florida 32611-0691, USA.
}

pregnancy recognition signal in ruminants is interferon tau (IFNT) secreted by the mononuclear trophectodermal cells of conceptuses during the peri-implantation period of pregnancy. This review focuses on mechanisms regulating pulsatile secretion of PGF by the uterine endometrium during the estrous cycle and the mechanism whereby IFNT signals pregnancy by silencing expression of receptors for estradiol-17 $\beta$ (ESR1), progesterone (PGR) and oxytocin (OXTR) in uterine luminal (LE) and superficial glandular (sGE) epithelia. IFNT has two key roles. First, it abrogates the uterine luteolytic mechanisms. Second, it induces expression of interferon regulatory factor 2 (IRF2) in uterine LE/sGE to silence expression of ESR1 and classical IFNT stimulated genes, while, in concert with progesterone (P4), enhancing expression of genes by uterine LE/sGE required for conceptus development, implantation and successful development of the conceptus to term. Cellspecific signaling pathways by which IFNT acts differentially on cells of the endometrium will also be discussed. 


\section{Conceptus development and implantation (see Bazer} and First, 1983).

After fertilization, embryos remain near the ampullaryisthmic junction of the oviduct before entering the uterus at about $72 \mathrm{~h}$ in ewes and 72 to $96 \mathrm{~h}$ in cows. Sheep embryos fail to develop beyond the early blastocyst stage if confined to the oviduct due to either the absence of factors essential for embryonic development or the presence of an embryotoxic factor(s). Migration of blastocysts between the uterine horns is rare in monovulatory ewes and cows. However, transuterine migration does occur in sheep, but not in cows, when there are multiple ovulations from the same ovary.

Elongation of sheep, goat and cow conceptuses occurs before implantation. Sheep blastocysts are spherical on d 4 $(0.14 \mathrm{~mm})$ and $10(0.4 \mathrm{~mm})$ before elongating to filamentous forms by d 12 (1.0 by 33mm), 14 (1 by $68 \mathrm{~mm}$ ) and 15 (1 by 150 to $190 \mathrm{~mm}$ ) of pregnancy. Elongation continues until the trophoblast extends through the uterine body and into the contralateral uterine horn between d16 to 17 and 20 of pregnancy. Bovine blastocysts are spherical on d 8 to 9 ( $0.17 \mathrm{~mm}$ diameter), oblong or tubular on days 12 to 13 (1.5 to $3.0 \mathrm{~mm}$ diameter) and oblong to filamentous on d 13 to 14 (1.4 by $10 \mathrm{~mm}$ ), before becoming filamentous on d 14 to 15 (2 by $18 \mathrm{~mm}$ ), 16 to 17 (1.8 by $50 \mathrm{~mm}$ ) and 17 to 18 (1.5 by $160 \mathrm{~mm}$ ) of pregnancy. The bovine conceptus occupies about two-thirds of the gravid uterine horn by $\mathrm{d} 17$ to 18; the entire gravid uterine horn by days 18 to 20, and extends into the contralateral uterine horn by d 24 of pregnancy.

Conceptus development in water buffalo is similar to that for cattle, but slightly accelerated to d 8 (Drost et al., 1986). Details of conceptus development in camelidae (camels, llama and alpaca) are not available. Females in those species are induced ovulators and ovulation is induced by intravaginal deposition of seminal plasma in bactrian camels (Ismail, 1987). Ovulation occurs 24-26 h post-coitum in llama and alpaca and 30-48 h post-coitum in camels. Camels ovulate from the right and left ovaries with equal frequency; however, almost $100 \%$ of the conceptuses develop in the left uterine horn. The right uterine horn seems incompetent to support conceptus development beyond about $50 \mathrm{~d}$ (embryo crown-rump length of 2-3 cm). Embryonic death losses are very high in alpaca and llama.

Conceptus development during the pre-implantation period for goats, buffalo and camelidae is similar to that for sheep and cows and elongation of the conceptus is a prerequisite for central implantation involving the trophoblast primarily. In sheep, the embryonic disc is not required for successful implantation. Central implantation in sheep, cattle, buffalo, goat and camelidae is superficial and noninvasive with increasing trophectoderm-uterine epithelial cell apposition and adhesion with no permanent erosion of uterine epithelium. These species exhibit central implantation and have placentae of the diffuse and cotyledonary types.

The uterine endometrium of ruminants includes both caruncular and intercaruncular tissue, and implantation involves both tissues. Trophoblast cells of sheep are united laterally by desmosomes and are low cuboidal until d 12, after which time they become columnar and more secretory by d 14. Microvilli are abundant over the surface of the trophectoderm prior to d 14, become shorter and less dense after d 14, and disappear as apposition with the uterine LE/sGE ensues. Microvilli on the surface of uterine LE/sGE are in contact with the smooth plasma membranes of trophectoderm by d 15 and penetrate into folds in the trophectoderm leading to close adhesion between these tissues. Trophectoderm cells also develop villous projections by d 13 that project into the openings of uterine glands during the third week of gestation. The microvilli immobilize the conceptus and facilitate uptake of secretions from uterine GE. Similar modifications of the bovine trophoblast occur, but slightly later. Adhesion between bovine trophectoderm and caruncular epithelium is detectable by d 16, but attachment between trophectoderm and uterine intercarunclular LE/sGE does not occur until d 18 to 19 of pregnancy.

Binucleate cells (BNC) appear in trophoblast of sheep and cow conceptuses by d 16 and 19, respectively and migrate into the uterine LE soon thereafter. Multinucleate giant cells are also present and form a syncytium at the trophectoderm:uterine LE interface. BNC migration occurs throughout pregnancy, but multinucleate cell formation ceases by about $\mathrm{d} 28$ in sheep. BNC formation, the presence of multinucleate giant cells, and migration of BNC are associated with degeneration of uterine LE and removal of those cells by phagocytosis, apotosis and/or perforinmediated cell death. There is restoration of the uterine LE later in pregnancy. The BNC are involved in: i) removal and replacement of uterine LE; ii) establishment of a syncytium between maternal and conceptus compartments for immunological protection of the conceptus; iii) production of ovine placental lactogen (CSH1); iv) production and transport of macromolecules; and v) immobilization of trophectoderm to accomodate microvillus interdigitation with uterine LE/sGE. The extra-embryonic mesoderm originates from the embryonic disc and migrates between the trophectoderm and extra-embryonic endoderm. The mesodermal layer divides and combines with trophectoderm to form the chorion and with endoderm to form the yolk sac. The mesoderm also contributes to formation of the amnion and allantois. These membranes form the placenta that provides for histotrophic (uterine histotroph) and hematotrophic (exchange of nutrients and gases between maternal to fetal-placental blood) nutrition of the 
embryo/fetus. Histotroph includes proteins and other molecules secreted into the uterine lumen by uterine epithelia, as well as proteins and other molecules, such as glucose and amino acids, transported into the uterine lumen to support growth and development of the conceptus.

The five phases of implantation in mammals include: i) shedding of the zona pellucida; ii) pre-contact and blastocyst orientiation; iii) apposition; iv) adhesion; and v) endometrial invasion (Guillomot, 1995). However, endometrial invasion does not occur in ruminants.

Shedding of the zona pellucida (Phase 1) : Morula (1632 cell) stage sheep embryos enter the uterus from the oviduct on $\mathrm{d} 4$ post-mating (d $0=$ estrus/mating), reach the blastocyst stage on d 6, and "hatch" from the zona pellucida between d 8 and 9. Loss of the zona pellucida allows the trophectoderm to expand and make contact with the uterine LE. On d 8, spherical blastocysts are about $200 \mu \mathrm{m}$ in diameter with about 300 cells. By d 10, blastocysts are 400 to $900 \mu \mathrm{m}$ in diameter and contain some 3000 cells. After d 10, the blastocyst or conceptus transitions to tubular and filamentous forms described previously.

Pre-contact and blastocyst orientation (Phase 2) : Between d 9 and 14 of pregnancy, there are no definitive cellular contacts between trophectoderm and LE, but sheep conceptuses become positioned and immobilized in the uterine lumen to undergo rapid elongation of trophectoderm. Between d 11 and 17 the conceptus elongates to $25 \mathrm{~cm}$, the primitive streak in the embryonic disc appears, and somites appear soon thereafter. Elongation of the conceptus is critical for central implantation and for production of IFNT to signal pregnancy recognition to ensure maintenance of a functional corpus luteum (CL) for production of $\mathrm{P} 4$, the hormone of pregnancy.

Apposition (Phase 3) : The trophectoderm is in close association with uterine LE. This is followed by unstable adhesion and then apposition between trophectoderm and uterine LE accompanied by a reduction in apical microvilli covering the trophectoderm between $\mathrm{d} 13$ and 15 of pregnancy. The LE undergoes similar modification for closer association with trophectoderm that involves interdigitation of cytoplasmic projections of trophectoderm and uterine LE beginning at the inner cell mass and spreading along the filamentous conceptus toward the end of the trophectoderm. The finger-like villi of trophectoderm which penetrate into the mouths of the uterine glands between d 15 to 18 disappear by d 20 of pregnancy. These villi anchor the peri-attachment conceptus and absorb secretions of uterine glands in sheep and cattle, but not goats.

Adhesion (Phase 4) : Conceptus trophectoderm is firmly adhered to uterine LE on $\mathrm{d} 16$ in caruncular and intercaruncular areas of endometrium and adhesion is complete on d 22 of pregnancy in sheep. Production of
IFNT ceases by d 21 of pregnancy in sheep as trophoblast giant BNC differentiate from the mononuclear trophoblast, but only mononuclear trophoblast cells adhere to uterine LE. The BNC produce CSH1 and $\mathrm{P} 4$ that regulate maternal physiology. The BNC arise from mononuclear trophectoderm cells by consecutive nuclear divisions without cytokinesis, migrate through the apical trophectoderm tight junctions of the chorion, and flatten as they become apposed to the apical surface of uterine LE. The BNC then fuse apically with uterine LE and form syncytia of trinucleate cells, thereby assimilating and replacing some of the uterine LE. The trinucleate cells enlarge due to continued BNC migration and fusion to form syncytial plaques linked by tight junctions that, in sheep, include 20 to 25 nuclei. The syncytial plaques eventually cover the caruncular surface and aid in formation of placentomes. The BNC migrate and fuse with uterine LE or their derivatives throughout pregnancy. Therefore, uterine LE persists but is modified to variable degrees, depending on species, by the migration and fusion of BNC with uterine LE. The sheep placenta is synepitheliochorial, being neither entirely syndesmochorial without uterine LE, nor completely epitheliochorial with apposed trophectoderm and uterine LE as the only anatomical interaction being interdigitated microvilli.

\section{The estrous cycle}

Uterine secretion of luteolytic pulses of PGF in sheep is dependent upon effects of P4, estradiol-17 $\beta$ (E2) and oxytocin (OXT) on uterine LE, sGE and glandular (GE) epithelia (Bazer et al., 1994; Thatcher et al., 1995). P4 acts on these epithelia to increase phospholipid stores (arachidonic acid source) and cyclooxygenase enzymatic activity necessary for conversion of arachidonic acid to PGF. OXT secreted by the CL and posterior pituitary acts through OXTR present on LE/sGE at specific stages of the estrous cycle to stimulate release of luteolytic pulses of PGF (Figure 1). Endometrial OXTR are present between estrus and about d 4 of the cycle, become low or undetectable between $\mathrm{d} 5$ and 13, and then increase rapidly on LE/sGE between $\mathrm{d} 14$ and 16 (luteolytic period) of the estrous cycle in ewes. In ewes, endometrial expression of PGR, ESR1 and OXTR is the default state since endometria of longterm ovariectomized ewes express high levels of these receptors. The effect of $\mathrm{P} 4$ on uterine expression of ESR1 and OXTR in long-term ovariectomized ewes is complex. Without P4 stimulation, uteri express ESR1 and OXTR, but do not produce PGF in response to OXT because P4 is required for uterine epithelia to accumulate phospholipid stores and cyclooxygenase activity. With P4 stimulation of long-term ovariectomized ewes, endometrial expression of ESR1 and OXTR is suppressed. During the estrous cycle of ewes, P4 acts via PGR to down-regulate expression of 


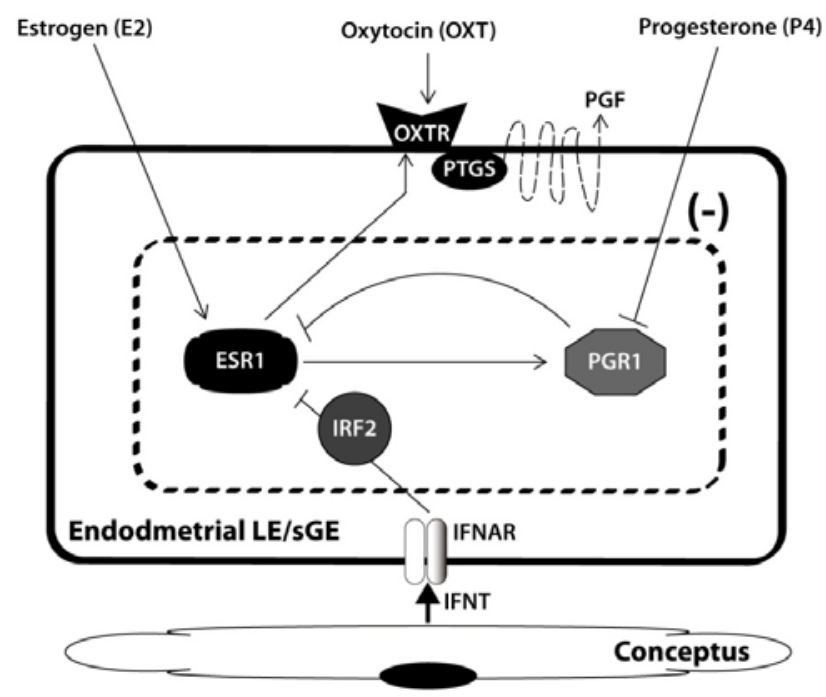

Figure 1. A schematic illustration of the current working hypothesis on hormonal regulation of the endometrial antiluteolytic mechanism and cross-talk between the conceptus and the maternal endometrium. During the estrous cycle, ESR1 expression increases and PGR expression decreases which allows E2 to induce OXTR expression, thereby allowing oxytocin from the posterior pituitary and/or CL to induce release of luteolytic pulses of prostaglandin $\mathrm{F}_{2 \alpha}$ (PGF). In contrast, during early pregnancy, secreted IFNT from fully elongated conceptus silences ESR1 expression which prevents E2-induced OXTR expression to prevent oxytocin-induced secretion of luteolytic pulses of PGF. Legend: IFNT = Interferon tau; IFNAR = Type I IFN receptor; PGR = Progesterone receptor; ESR1 = Estrogen receptor alpha; OXT = Oxytocin; OXTR = Oxytocin receptor; IRF2 = Interferon regulatory factor 2; LE = Luminal epithelium; sGE = Superficial ductal glandular epithelium (Adapted from Song et al. (2009)).

ESR1 and OXTR, but by d 13 of the estrous cycle and pregnancy, P4 down-regulates PGR, its own receptor, which allows expression of ESR1, E2-induced expression of OXTR and OXT-induced pulsatile release of PGF on d 15 and 16 of the estrous cycle. Thus, $\mathrm{P} 4$ prepares the uterus for production of luteolytic PGF if pregnancy is not established, but P4 is also critical for preparing the uterus for support of conceptus development for the establishment and maintenance of pregnancy.

Progesterone, acting via PGR, inhibits synthesis of OXTR by uterine LE/sGE for 10 to $12 \mathrm{~d}$; the period known as the "P4-block" (McCracken et al., 1984). P4 downregulates PGR by d 12 to 13 of the cycle to end the "P4block" and permit rapid increases in E2 to act via ESR1 to induce expression of ESR1 and OXTR (Spencer and Bazer, 1995a). In cyclic ewes, endometrial PGR protein and mRNA decrease from d 10 to 14 and then increase most rapidly on d 15-16 of the estrous cycle. This coincides with increased expression of ESR1 protein and mRNA, and OXTR protein and mRNA in uterine LE/sGE between d 14 and and day of onset of estrus (Bazer et al., 1994; Thatcher et al., 1995). During the luteolytic period, most pulses of OXT induce a pulse of PGF responsible for luteolysis. The PGF pulse frequency may be less than that for OXT because of the time required for replenishment of pools of phospholipids from which arachidonic acid can be mobilized for synthesis of PGF or the time required for OXTR recycling. Platelet activating factor (PAF) appears to determine the sensitivity of uterine epithelia to OXT and, therefore, the inter-pulse interval for secretion of PGF in ewes (Chami et al., 1999).

Treatment of ewes or goats with an OXT antagonist, and passive or active immunization of ewes against OXT or continuous infusion of OXT to down-regulate OXTR prevents or significantly delays luteolysis. E2 up-regulates OXTR and enhances OXT-induced pulsatile release of luteolytic PGF (Spencer et al., 1995a; Fleming et al., 2006). Thus, P4, PGR, E2, ESR1, OXT and OXTR have central roles in the mechanism for uterine secretion of luteolytic PGF.

Estradiol enhances OXTR synthesis and post-receptor events mediated by OXT to ensure a PGF pulse frequency necessary for luteolysis. In the absence of E2 or ESR1 in uterine LE/sGE, the OXT pulse frequency or an undefined E2-sensitive PGF pulse generator is inadequate to induce luteolysis. Effects of E2 on development of the luteolytic mechanism have been demonstrated. A single injection of $500 \mu \mathrm{g}$ E2 to cyclic ewes on d 9 or d 10 results in luteolysis through the following sequence of events: i) formation of OXTR within $12 \mathrm{~h}$; ii) OXT stimulation of its second messenger system by $24 \mathrm{~h}$; iii) episodic secretion of PGF by $35 \pm 3 \mathrm{~h}$; iv) functional luteolysis and decreasing concentrations of P4 in plasma at $42 \pm 3 \mathrm{~h}$; and v) estrous behavior at $67 \pm 9 \mathrm{~h}$. Uterine release of about five pulses of PGF per $24 \mathrm{~h}$ is required for complete regresssion of CL (McCracken et al., 1999). Pulsatile release of OXT and PGF 
between d 15 and 17 continues until the CL is depleted of its finite stores of OXT. Thus, E2 increases in ESR1 mRNA, then ESR1 protein and then OXTR mRNA and protein sequentially, and this is followed by pulsatile release of PGF and luteolysis (Spencer et al., 1995a).

The limiting factors in uterine epithelia controlling PGF secretion are the availability of arachidonic acid and the rate of PGF synthesis by prostaglandin endoperoxide $\mathrm{H}$ synthase (PTGS2). After P4 priming, low amplitude pulses of PGF secretion occur in both cyclic and pregnant ewes on d 13-14 and d 14-15 in cattle. Following these initial subluteolytic pulses of PGF secretion, high amplitude pulses of PGF induce the final stages of $\mathrm{CL}$ regression. Endometrial OXTR induced in the latter stages of the estrous cycle of ewes and cows, and a positive feedback loop between uterine PGF and OXT secretion by luteal cells induce pulsatile PGF secretion by increasing phospholipase C (PLC) activity leading to the production of inositol trisphosphate $\left(\mathrm{IP}_{3}\right)$ and diacylglycerol (DAG). These intracellular messengers enhance PGF secretion by increasing expression of phospolipase A2 (PLA2) activity that increases available arachidonic acid for metabolism by PTGS2 to PGF.

Endometrial tissues from ovariectomized ewes receiving steroid replacement to permit OXT-induced increases in PGF secretion respond similarly to melittin, a stimulator of PLA2, and OXT (Lee and Silvia, 1994). Further, aristolochic acid, an inhibitor of PLA2, inhibits the ability of melittin and OXT to increase PGF secretion. But, inhibition of PLA2 activity does not block OXT-induced increases in PLC activity or inhibit increase in PGF secretion in response to arachidonic acid. Thus, OXT likely acts via an intracellular mechanism proximal to PLA2 to stimulate PGF secretion. The PLA2 pathway and PLC activity appear to regulate PGF secretion during the preluteolyic and luteolytic periods. Thus, expression of receptors for ESR1 and OXT, as well as PTGS2 activity are likely targets for candidate antiluteolytic signals for pregnancy recognition and establishment of pregnancy.

\section{Early pregnancy factors}

Pregnancy factors are secretory products of the trophoblast for communication between the conceptus and maternal system. One of the earliest pregnancy factors, PGE2, allows the oviduct of mares to recognize transport embryos into the uterine lumen whereas unfertilized oocytes are retained in the oviduct (Weber et al., 1991; Robinson et al., 2000). There are also reports of an "early pregnancy factor" (EPF) produced during the preimplantation period that affects maternal lymphocytes (Morton, 1985). The EPF in serum is believed to be from maternal tissue and to exist as EPF-A and EPF-B. The EPF$\mathrm{A}$ is estrus-dependent, produced by the oviduct and activated by EPF-B after which it binds to lymphocytes. The EPF-B is the pregnancy-dependent component or "ovum factor" released from the ovary in response to fertilization and produced to the blastocyst stage of development. The results from studies of EPF with rodents, ewes, cows and pigs are controversial.

Another pre-implantation response to pregnancy is an increase in circulating concentrations of platelet activating factor (PAF) on d 2 of pregnancy in mice (O'Neill, 1990). Thrombocytopenia occurs within $3 \mathrm{~h}$ after transfer of fertilized ova to pseudopregnant recipients and the reduction in platelets is positively correlated $(r=0.86)$ with the number of embryos transferred. An increase in PAF III may be responsible for the thrombocytopenia. Sixteen-cell mouse embryos release PAF III into culture medium which causes thrombocytopenia and similar effects were induced with 1-O-alkyl-2-acetyl-sn-glycero(3) phosphocholine (PAF-acether), a potent platelet activating factor (O’Neill et al., 1990).

Ruminant conceptuses either produce or induce production of EPFs that cause the maternal system to respond and support pregnancy. Viable conceptuses communicate with or modify the maternal system to: i) allow for their survival as semi-allografts; ii) stimulate vasodilation and angiogenesis to increase uterine blood flow and substrate delivery to the pregnant uterus; iii) stimulate active transport of nutrients into the uterine lumen from maternal tissues and fluids; iv) regulate intrauterine migration of blastocysts; v) stimulate placentation; and vi) signal pregnancy recognition for establishment and maintenance of pregnancy. Ruminant conceptuses secrete proteins, steroids and prostaglandins that regulate these various responses (Bazer et al., 2010; Simmons et al., 2010; Bazer et al., 2011a; Dorniak et al., 2011). An essential signal produced at a precise time and in adequate amounts to allow maintenance of CL function and continued production of P4 is IFNT (Bazer et al., 2010) which is the candidate molecule for pregnancy recognition associated with CL maintenance (Short et al., 1991). In ruminants, the signal is IFNT (Bazer et al., 2010).

\section{Pregnancy recognition signals responsible for $C L$ maintenance}

Sheep, cattle and goats have estrous cycles of about 17 , 21 and 20 d, respectively. An ovulatory surge of luteinizing hormone (LH) is coincident with onset of estrus (d 0) and initiates events which culminate in ovulation about $30 \mathrm{~h}$ later. With maturation of the CL, concentrations of P4 in peripheral blood are maximum in diestrus and, in cyclic females, PGF-induced luteolysis occurs in late diestrus (d 15-16 for sheep; d 16-18 for cattle and goats). The dynamics of PGF secretion are altered in pregnancy because E2- and OXT-induced secretion of PGF is suppressed 
(Figure 1). In pregnant cows, luteolytic pulses of PGF are abolished, but there is an increase in basal secretion of PGF (Thatcher et al., 1995; Mishra et al., 2003). In ewes, luteolytic pulses of PGF are also abolished and basal concentrations of PGF in blood are two- to three-fold greater in pregnant than cyclic ewes (Fincher et al., 1986). The antiluteolytic hormone in ruminants is IFNT which exerts paracrine effects on the endometrium to abrogate development of the luteolytic mechanism responsible for endometrial production of luteolytic pulses of PGF.

In ewes, IFNT induces expression of IRF2, a potent suppressor of transcription, which silences transcription of ESR1. In the absence of ESR1, E2 is unable to induce expression of OXTR in uterine LE/sGE and this abrogates development of the endometrial luteolytic mechanism for OXT-induced luteolytic pulses of PGF (Bazer et al., 2011a). IFNT is the first major protein secreted by mononuclear cells of ovine trophectoderm. Other conceptus or uterine products secreted during pregnancy, e.g., PGE2 and PAF, may exert secondary luteal protective effects.

There are differences in lipid metabolism and intracellular regulatory pathways of endometrial tissue from cyclic and pregnant animals. Endometrial PLA2 activity is lower in pregnant compared to cyclic ewes on d 14 and 16 (Tamby et al., 1993) and OXT does not induce PLC activity in endometrial tissue from d 12, 14 and 16 of pregnancy (Silvia and Raw, 1993). However, OXT and arachidonic acid treatment of endometrial tissue from pregnant ewes increases secretion of PGF. The stimulatory effect of arachidonic acid on PGF secretion suggests that arachidonic acid may be limiting in endometria of pregnant ewes which is consistent with low PLA2 activity. Basal secretion of endometrial PGF in enhanced by $\mathrm{Ca}^{++}$in both cyclic and pregnant cows on d 17 (Danet-Desnoyers et al., 1995; Thatcher et al., 1995), but exogenous PLA2 increased basal secretion of PGF only in explants from pregnant cows. Exogenous arachidonic acid also stimulated PGF secretion in cyclic and pregnant cows, but the response was less in endometrial explants from pregnant cows. Thus, the availability of arachidonic acid may also limit secretion of PGF in cattle during pregnancy.

\section{Endometrial prostaglandin synthesis inhibitor}

The antiluleolytic effect of the bovine conceptus may include induction of an intracellular inhibitor of PTGS2 called EPSI (endometrial prostaglandin synthesis inhibitor) (Thatcher et al., 1994; Thatcher et al., 1995). EPSI was identified as linoleic acid (18:2n-6), a fatty acid that is a competitive inhibitor of PTGS2. The bovine conceptus alters lipid metabolism in the endometrium to decrease arachidonic acid and increase linoleic acid. This may reduce synthesis of PGF as arachidonic acid and linoleic acid compete as substrates for metabolism by PTGS2. The presence of the conceptus in sheep decreases PLA2 activity, but not PTGS2 gene expression.

\section{Interferon tau (IFNT)}

Interferon tau isoforms are a unique 172 amino acid subclass of Type I IFNs produced in massive amounts by trophectoderm of ruminants by genes lacking a viral response element (Roberts et al., 1992). The nomenclature for IFNT is based on high cross-species sequence homology of this Type I IFN and unique regulation of its expression (Roberts et al., 1992). IFNT is a unique antiluteolytic pregnancy recognition signal in ruminants expressed by mononuclear cells of trophectoderm as conceptuses transition from spherical to tubular to filamentous forms during the peri-implantation period of pregnancy. However, IFNT also has antiviral, antiproliferative and immunomodulatory roles characteristic of other Type 1 IFNs (Bazer et al., 2009).

A component of uterine secretions produced in response to P4 affects onset of secretion and amount of secretion of IFNT (Hernandez-Ledezma et al., 1992; Satterfield et al., 2008). Bovine embryos produced by in vitro maturation and fertilization (IVM-IVF) secrete little or no IFNT at the blastocyst stage; however, embryos transferred to the uterus and recovered $4 \mathrm{~d}$ later secreted copious amounts of IFNT. Imakawa et al. (1993) and Loureiro et al. (2011) suggest that granulocyte-monocyte-macrophage colony stimulating factor (CSF2), secreted by uterine endometrium of sheep, enhanced secretion of IFNT by ovine and bovine conceptuses. Nephew et al. (1990) identified an activator protein 1 (AP1)-like regulatory element (ATGGGTCAGA) at position -929 of the ovine IFNT gene which suggests that factors affecting AP1 enhancer activity, like GM-CSF, influence ovine IFNT gene expression. Xavier et al. (1991) demonstrated coordinate expression of IFNT and FOS in sheep conceptuses during early pregnancy; however, the function(s) of this element has not been demonstrated. More recently, Cook et al. (2009) reported that fibroblast growth factor 2 (FGF2) affects IFNT gene expression. Kim et al. (2011a; 2011b) reported that arginine stimulates IFNT secretion by an ovine trophectoderm cell line and explants cultures of d 16 ovine conceptuses. Further, Satterfield et al. (2008) found that treatment of ewes with P4 from d 1.5 after onset of estrus significantly advanced the rate of conceptus development along with coordinate increases in the amounts of FGF10 and arginine in uterine flushings on d 9 and 12 of pregnancy. Collectively, these results suggest that uterine cytokines, growth factors and/or select nutrients may influence secretion of ovine IFNT.

\section{Type I IFN receptors}

Ovine IFNT binds to a receptor with an apparent molecular weight of $100 \mathrm{kDa}$ in ovine endometrial 
membrane preparations (Roberts et al., 1992). The human type I IFN receptor (IFNAR1/IFNAR2) is a heterodimer present on essentially all human cell types. It is a 95-100 $\mathrm{kDa}$ transmembrane glycoprotein generated from a $2.7 \mathrm{~kb}$ mRNA encoding a $65 \mathrm{kDa}$ protein with 15 potential asparagine-linked glycosylation sites. Binding of IFNT to ovine endometrium activates the classical janus kinase (JAK) and signal transducer and activator of transcription (STAT) cell signaling pathway, but may also activate nonclassical cell signaling via the mitogen activated protein kinase (MAPK) and mechanistic target of rapamycin (MTOR) cell signaling pathways (Platanias, 2005).

\section{Antiluteolytic activity of IFNT}

Ovine IFNT is secreted between d 10 and 21 of pregnancy, has a molecular weight of 19,000 , and binds to the common IFNAR1/IFNAR2 receptor for Type 1 IFNs. Infusion of highly purified native IFNT (Vallet et al., 1991) or recombinant IFNT (Spencer et al., 1995b) into the uterine lumen from d 12 to 14 or $\mathrm{d} 11$ to 15 of the estrous cycle extends the interestrous interval and CL lifespan; therefore, IFNT alone appears to be the antiluteolytic factor produced by ovine conceptuses. As noted previously, IFNT acts as a paracrine antiluteolytic hormone to abrogate development of the luteolytic mechanism dependent on actions of E2 and OXT by silencing expression of ESR1 and OXTR genes in uterine LE/sGE. However, there is evidence that IFNT also has systemic effects as circulating immune cells increase expression of classical IFN stimulated genes (ISG) such as 2', 5' oligoadenylate synthase (OAS1) (Schmitt et al., 1993), ISG 15 (Han et al., 2006) and MX (Yankey et al., 2001) such that the CL becomes more resistant to luteolysis in ewes infused systemically with IFNT (Bott et al., 2010). Total recoverable IFNT (ng) in uterine flushings from ewes begins on d 10 and increases as conceptuses change morphologically from spherical (312 $\mathrm{ng})$, to tubular (1,380 ng) to filamentous (4,455 ng) forms between d 12 and 13 (Ashworth and Bazer, 1989). Successful transfer of embryos to cyclic ewes can occur as late as d 12, i.e., 48 to $72 \mathrm{~h}$ prior to the luteolytic period on d 15-16 after onset of estrus. Thus, IFNT is secreted prior to the luteolytic period to silence expression of ESR1 and OXTR genes to abrogate the mechanism for OXT-induced secretion of luteolytic pulses of PGF by uterine LE/sGE. There are no effects of IFNT on PGR protein or mRNA; however, as noted earlier, all endometrial epithelia cease expressing PGR by d 13 after onset of the estrous cycle and pregnancy, but endometrial stromal cells and myometrium express receptors for PGR throughout pregnancy (Bazer et al., 2011a).

\section{Cattle}

Intrauterine injections of recombinant ovine IFNT
(roIFNT) and bovine IFNT (rbIFNT) extend CL lifespan, interestrous interval and inhibit OXT-induced secretion of PGF by the uterus. There is significant variability among cows in CL lifespan 24 to $29 \mathrm{~d}$ for roIFNT and 27 to $35 \mathrm{~d}$ for rbIFNT and responsiveness to OXT. Thus, uterine responsiveness to IFNT may depend on uterine receptor kinetics and/or efficiency of post-receptor cell signaling. The ability of rbIFNT to attenuate basal and OXT-induced secretion of PGF by primary cultures of bovine endometrial epithelial cells from cyclic cows on d 15 of the estrous cycle indicates the paracrine regulatory potential of the trophectoderm (Meyer et al., 1995; Thatcher et al., 1995). A $50 \%$ inhibition of basal and OXT-induced secretion of PGF and PGE2 from epithelial cells was obtained with a dose of $1 \mathrm{ng} / \mathrm{ml}$ rbIFNT. Inhibition of secretion of prostaglandins was cell-specific since secretion of PGF and PGE2 by stromal cells was not affected by either IFNT or OXT (Danet-Desnoyers et al., 1994).

The effect of rbIFNT in vivo on endometrial OXTR and in vitro secretion of PGF from endometrial epithelial cells indicated that OXTR binding was only slightly attenuated by rbIFNT (Meyer et al., 1995; Thatcher et al., 1995). Cows treated with rbIFNT in vivo secreted less PGF in vitro; however, control cows had enhanced basal secretion of PGF, and OXT-stimulated secretion of PGF was inhibited by in vitro treatment with either 2 or $50 \mathrm{ng} / \mathrm{ml}$ rbIFNT. Although rbIFNT administered in vivo reduced in vitro PGF secretion, epithelial cells in the in vitro culture system maintained their responsiveness to OXT in both the absence and presence of rbIFNT ( 2 and $50 \mathrm{ng} / \mathrm{ml}$ ). Restoration of OXT responsiveness in vitro may be due to up-regulation of OXTR expression. Endometrial OXTR numbers are low in pregnant compared to cyclic cows ( $563 \pm 117$ versus $18 \pm 5$ $\mathrm{fmol} / \mathrm{mg}$ protein) during the luteolytic period. The rbIFNT likely inhibits endometrial ESR1 and OXTR gene expression to prevent luteolysis in cows as is the case for ewes. Intrauterine infusion of bovine conceptus secretory proteins in cyclic cows between d 15 to 21 increases the interestrous interval from 23 to 24 d to 30 to 39 d (Knickerbocker et al., 1986a) and inhibits uterine production of PGF in response to exogenous E2 (Knickerbocker et al., 1986b). Bovine endometrium contains EPSI during the estrous cycle and pregnancy and production of EPSI is stimulated by bIFNT (Helmer et al., 1989). The PGE2 produced by bovine conceptuses may have a luteal protective role, but this has not been established. Bovine conceptuses also secrete limited amounts of P4, androstenedione and E2 as well as $5 \beta$-reduced androgens and progestins, but the role(s) of these steroids in pregnancy is not known (Eley et al., 1983).

\section{Goat}

Pregnancy recognition in goats occurs around d 17 as goat conceptuses secrete caprine IFNT (cIFNT) between d 
16 and 21 of pregnancy (Bazer et al., 2009; Bazer et al., 2011a). The cIFNT can be immunoprecipitated with antiserum to ovine IFNT and is presumed to be the antiluteolytic protein in goats. Pulsatile release of OXT and PGF are suppressed in pregnant compared to cyclic goats between d 10 to 12 and estrus or d 20 of pregnancy suggesting that the antiluteolytic mechanism mediated by IFNT is similar for sheep, cows and goats.

\section{Progesterone, IFNT and progestamedins}

Interferon tau, the signal for pregnancy recognition in ruminants, exerts multiple effects on the uterus that are required for establishment and maintenance of pregnancy (Bazer et al., 2009; Bazer et al., 2010; Bazer et al., 2011a). A primary function of IFNT is to abrogate development of the uterine luteolytic mechanism to ensure maintenance of ovarian CL to produce $\mathrm{P} 4$, the hormone essential for establishment and maintenance of pregnancy. The second key role of IFNT is to silence ESR1 gene expression to ensure that E2 is unable to induce expression of $P G R$ in endometrial epithelia as loss of PGR in uterine epithelia is a prerequisite for implantation. $\mathrm{P} 4$ is permissive to actions of IFNT and other hormones secreted by the trophectoderm/ chorion on uterine epithelia. The paradox is that cessation of expression of PGR and ESR1 by uterine epithelia is a prerequisite for uterine receptivity to implantation, as well as expression of genes by uterine LE/sGE and GE for secretion of proteins and transport of molecules into the uterine lumen required for conceptus development (Bazer et al., 2011b). These genes may be induced by P4 alone, IFNT alone or induced by $\mathrm{P} 4$ and further stimulated by IFNT in uterine LE/sGE, GE and SC (Table 1). Down-regulation of PGR in uterine LE results in loss of MUC1 (mucin 1, cell surface associated) which is a prerequisite for attachment of conceptus trophectoderm to uterine LE for initiation of implantation (Carson et al., 2002). Silencing expression of $P G R$ in uterine epithelia is preceded by $\mathrm{P} 4$ actions via PGRpositive uterine stromal cells (SC) to induce expression of one or more progestamedins, e.g., fibroblast growth factor-7 (FGF7) and -10 (FGF10), and hepatocyte growth factor (HGF) in the ovine uterus. These growth factors can exert paracrine effects on uterine LE/sGE, GE and conceptus trophectoderm that express receptors for FGF7 and FGF10 (FGFR2IIIb) and HGF (MET; protooncogene MET); however, in ewes, FGF10 appears to be the primary progestamedin expressed by uterine SC (Chen et al., 2000a; Satterfield et al., 2008; Chen et al., 2011b).

Interferon tau and P4 stimulate expression of genes during the peri-implantation period of pregnancy in ewes (Table 1). One gene induced by IFNT alone in uterine LE/sGE is WNT7A, while P4 alone induces expression of: i) endogenous Jaksekete retrovirus in LE/sGE and GE; ii)
MET in LE/sGE and GE; iii) GLYCAM1 in LE/sGE; iv) MUC1 in LE; and v) PRLR in GE (Bazer et al., 2009; Bazer et al., 2010; Bazer et al., 2011b). In addition, P4 and placental lactogen (CSH1) induce expression of serine protease inhibitor and calcium binding proteins (SERPIN (also known as UTMP) and STC1 in uterine GE.

Genes induced by $\mathrm{P} 4$ and further stimulated by IFNT in uterine LE/sGE include: i) morphogens (GRP, IRF6); ii) proteases (CTSL); iii) protease inhibitors (CST3); iv) mediators of cell migration and adhesion including SPP1, galectin 15 (LGALS15), periostin (POSTN) and insulin-like growth factor binding protein 1 (IGFBP1); v) hypoxia inducible factors (HIF1A and HIF2A) that stimulate angiogenesis and erythropoiesis; vi) hydroxysteroid dehydrogenase 11B (HSD11B1) that mediates corticosterone metabolism and expression of glucocorticoid recetors (GCCR); vii) synthesis of prostaglandins (PTGS2) ; and viii) IRF2 a potent repressor of transcription (Bazer et al., 2009; Bazer et al., 2010; Bazer et al., 2011a). The uterine LE/sGE in closest proximity to or adhered to conceptus trophectoderm express these unique genes because IFNT induces expression of IRF2 in uterine LE/sGE to silence expression of ESR1, STAT1, STAT2 and IRF9. Therefore, this unique set of genes is induced by $\mathrm{P} 4$ and IFNT in uterine LE/sGE that lack both STAT1 and IRF9 (Figure 2). The uterine LE/sGE likely respond to P4 via a uterine stromal cell-derived progestamedin, particularly FGF10; therefore, effects of IFNT are mediated via a JAK/STAT-independent cell signaling pathway (Figure 3). P4 stimulates expression of both HGF and FGF10 by ovine uterine stromal cells. Recent reviews provide insight into the roles of proteins encoded for by genes expressed by ovine uterine LE/sGE that are induced by IFNT, P4 or the combined actions of P4 and IFNT (Bazer et al., 2009; Bazer et al., 2010; Bazer et al., 2011a; Bazer et al., 2011b).

\section{Model of IFNT action on endometrial epithelial cells}

Classical ISGs are expressed by maternal immune cells, as well as uterine GE and SC that do not express IRF2 and therefore respond to IFNT via the classical JAK/STAT cell signaling pathway (Figure 2). Endometrial proteins induced by IFNT e.g., B2M ( $\beta_{2}$-microglobulin) in sheep (Vallet et al., 1991) and 12 and $28 \mathrm{kDa}$ ubiquitin-like proteins in cattle (Rueda et al., 1993), may be important markers of gene expression in response to early activated transcription factors that bind to IFN stimulated response elements (ISRE) on target genes (Figure 2). Detailed studies of genes induced by IFNT (12 and $28 \mathrm{kDa}$ proteins, and 2,5'oligoadenylate synthetase (Short et al., 1991), Mx protein (Charleston and Stewart, 1993 ; Ott et al., 1995) or inhibited by IFNT (ESR1 and OXTR) are necessary to elucidate intracellular cell signaling mechanisms responsible for decreased endometrial secretion of luteolytic PGF. 
Table 1. Genes expressed in response to interferon tau, progesterone, and prostaglandins in ovine uteri

\begin{tabular}{|c|c|c|c|}
\hline Regulation of expression $^{\mathrm{a}}$ & Cell specific expression $^{\mathrm{b}}$ & Gene & Function \\
\hline \multirow[t]{18}{*}{ IFNT } & LE/sGE & IRF2 & Transcriptional repressor \\
\hline & & Wnt7A & Morphogen \\
\hline & $\mathrm{LE} / \mathrm{GE}$ & ISG12 & Antiviral response \\
\hline & SC & GBP2 & Member of GBP family/GTPase \\
\hline & & IFIH1 & Antiviral, growth suppression, apoptosis \\
\hline & & IFIT1 & Antiviral response \\
\hline & & IRF1 & Transcriptional regulator \\
\hline & SC/GE & B2M & Antiviral response \\
\hline & & DDX58 & Antiviral response/Gene expression \\
\hline & & IRF9 & Cell signaling/Gene expression \\
\hline & & MIC & Antiviral response \\
\hline & & NMI & Transcription regulator/Gene expression \\
\hline & & OAS & Antiviral/Cell growth/Differentiation/Apoptosis \\
\hline & & PLSCR1 & Endofacial membrane protein/Antiviral \\
\hline & & RSAD2 & Antiviral response \\
\hline & & STAT1 & Cell signaling/Gene expression \\
\hline & & STAT2 & Cell signaling/Gene expression \\
\hline & LE/GE/SC & MX & Antiviral/Intracellular protein/Vesicle trafficking \\
\hline \multirow[t]{17}{*}{ P4/IFNT } & LE/sGE & CST3 & Protease inhibitor \\
\hline & & CSTL & Protease \\
\hline & & HIF1A & Erythropoiesis, angiogensis, glycolysis \\
\hline & & HIF2A & Erythropoiesis, angiogensis, glycolysis \\
\hline & & IGFBP1 & Cell migration and adhesion \\
\hline & & LGALS15 & Cell migration and adhesion \\
\hline & & LIFR & LIF receptor \\
\hline & & SLC2A1 & Glucose transporter \\
\hline & & SLC5A11 & Sodium/Glucose co-transporter \\
\hline & & SLC5A1 & Neutral amino acid transporter \\
\hline & & SLC7A1 & Cationic amino acid transporter \\
\hline & & SLC7A2 & Cationic amino acid transporter \\
\hline & $\mathrm{LE} / \mathrm{sGE} / \mathrm{GE}$ & GRP & Morphogen \\
\hline & & IRF6 & Cell proliferation and differentiation \\
\hline & SC/GE & ISG15 (= UCRP) & Ubiquitination of proteins \\
\hline & GE & IL6ST & Cell signaling for immunoregulation \\
\hline & Eosinophils & MCP1/MCP2 & Cell death \\
\hline \multirow[t]{3}{*}{ P4/IFNT/PG } & LE/sGE & HSD11B1 & Corticosterone to cortisol \\
\hline & & NRC31 & Glucocortoid receptor \\
\hline & & PTGS2 & Synthesis of prostaglandins \\
\hline
\end{tabular}

${ }^{\mathrm{a}}$ Regulation of expression. P4, induced by progesterone (P4); and P4/IFNT, induced by progesterone (P4) and further stimulated by interferon tau (IFNT); P4/IFNT/PG, induced by progesterone (P4) and further stimulated by interferon tau (IFNT) and prostagland (PG).

${ }^{\mathrm{b}}$ Genes expressed by uterine luminal (LE), superficial glandular (sGE) and glandular (GE) epithelia, as well as stromal cells (SC).

\section{Antiluteolytic strategies to improve embryonic survial}

Exogenous interferons : Supplementation of inseminated animals with exogenous IFNT during the pregnancy recognition period may compensate for inadequate secretion of IFNT by conceptuses that are delayed in their development. Due to a limited supply of recombinant ovine or bovine IFNT, field testing of its potential fertility enhancing effects have been limited.
Therefore, rbIFNA (approximately 50\% amino acid sequence homology with bIFNT and oIFNT) has been used to determine effects on CL lifespan, binding to endometrial receptors, endometrial protein secretion, OXT-induced secretion of PGF in vivo and induction of 2,5'oligoadenylate synthetase in endometrium (Thatcher et al., 1995).

A series of fertility experiments with sheep treated with 
rbIFNA provided what appeared to be promising results, but the controls used for comparisons were insufficient. Twice daily injections of rbIFNA (2 mg) increased conception rates when injected on d 12 to 16 (92 vs. 76\%; Nephew et al., 1990); d 11-18 (80 vs. 65\%; Schalue-Francis et al., 1991); and d 11-18 (76 vs. 69\%; Martinod et al., 1991). Pregnancy rates for ewes treated with rbIFNA were (76 to $92 \%)$ greater than those for ewes treated with the placebo (62\%). However, these experiments did not include data from mated ewes that were not handled twice daily. Therefore, one cannot conclude that treatment with rbIFNA improved fertility or if it was only beneficial in overcoming effects of stress on handling and injection. In one study (Davis et al., 1992), the pregnancy rates were $80 \%$ for ewes treated with rbIFNT, $62 \%$ for ewes treated with placebo and $88 \%$ for ewes in the same barn and mated during the same period of time, but not handled and injected daily. In contrast to effects of rbIFNA in ewes, administration of
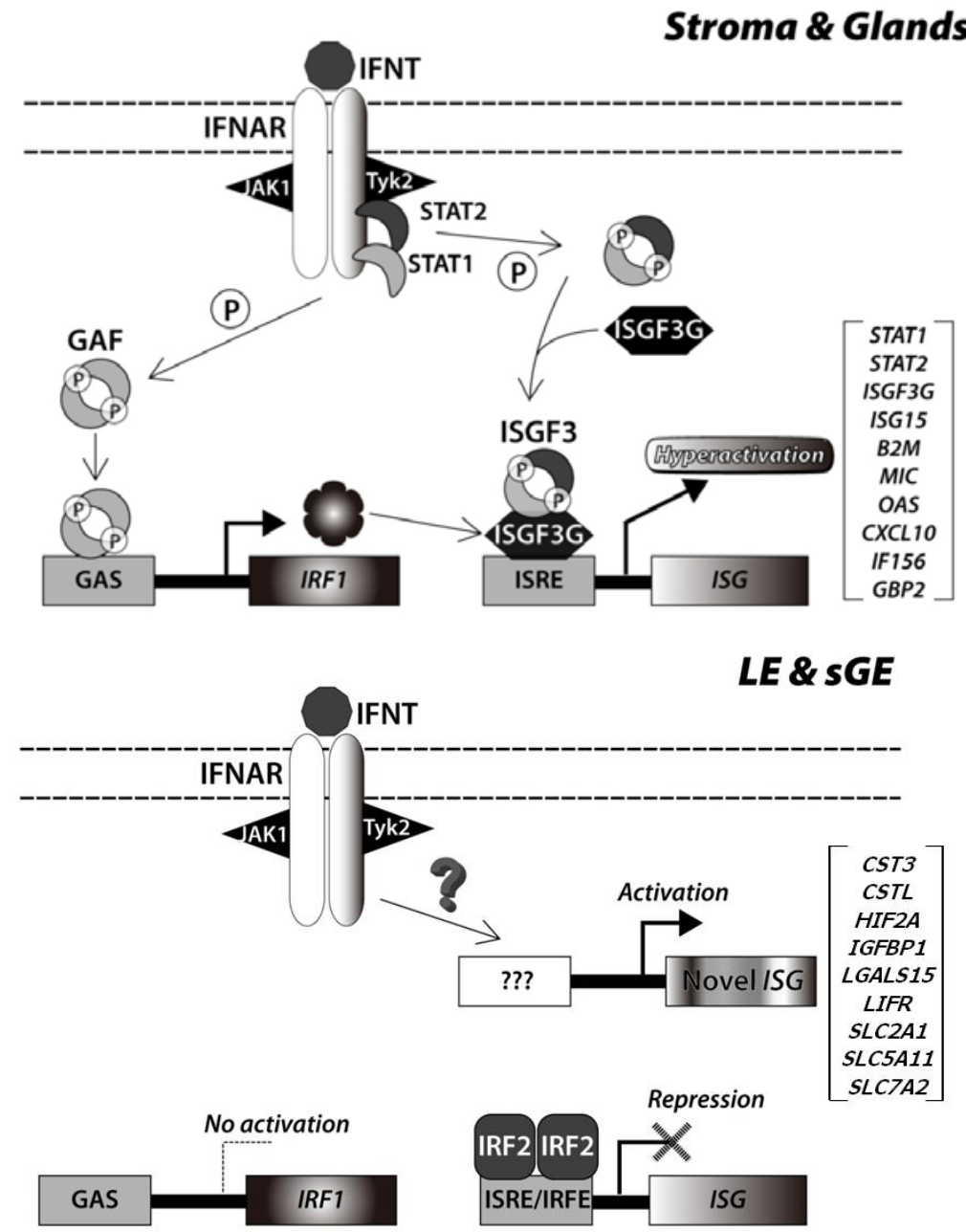

Figure 2. A schematic illustration of the current working hypothesis on IFNT signaling in ovine uterine stroma and uterine glandular epithelium compared to uterine luminal (LE) and supferficial glandular (sGE) epithelia. IFNT binds to a common Type I IFN receptor, IFNAR1 and IFNAR2, containing tyrosine kinase such as JAK1 and TYK2 to activate the JAK/STAT cell signaling pathway. Phosphorylated STAT1 binds phosphorylated STAT2 to form a heterodimer and translocates to the nucleus after forming a heterotrimeric transcriptional complex by binding with ISGF3G, collectively termed ISGF3. In addition to STAT1/2 heterodimerization, Type I IFN induces formation of phosphorylated STAT1 homodimers termed GAF. In the nucleus, ISGF3 binds to IFN-stimulated response element (ISRE) in promoter regions of ISGs to activate transcription in cooperation with several coactivators. Similarly, GAF enters the nucleus, binds to GAS elements, and stimulates transcription of ISGs. IFNT-induced IRF2 blocks expression of classical interferon stimulated genes in uterine LE/sGE. Legend: IFNT = Interferon tau; IFNAR = Type I IFN receptor; JAK1 = Janus kinase 1; TYK2 = Tyrosine kinase 2; STAT = Signal transducers and activators of transcription; GAF = Gamma interferon activation factor; GAS = Gamma interferon activation sequence; IRF1 = Interferon regulatory factor 1; ISGF3G = IFN-stimulated transcription factor 3, gamma 48-k Da; ISGF3 = IFN-stimulated transcription factor 3; ISRE = IFN-stimulated response element; ISG = IFNT-stimulated gene; ISG15 = IFNTstimulated gene 15; B2M = beta-2-microglobulin; $\mathrm{MHC}=$ Major histocompatibility complex; OAS = Oligoadenylate synthetase; CXCL10 = Chemokine C-X-C motif ligand 10; IFI56 = Interferon-induced protein 56; GBP2 = Guanylate binding protein 2, interferon inducible (Adapted from Song et al. (2009)). 
rbIFNA to cattle decreased conception rates by about $10 \%$, probably due to induced hyperthermia and acute decreases in plasma progesterone caused by decreased LH secretion (Barros et al., 1992). Ott et al. (1997) reported on ewes treated subcutaneously with $0,2,4$ or $6 \mathrm{mg} / \mathrm{d}$ roIFNT on d 12 of the estrous cycle. Rectal temperature, respiration rate and cortisol increased in response to all dosages of roIFNT with peak values at $150-180$ min post-injection, and concentrations of $\mathrm{P} 4$ declined from 120 to 360 min post- treatment and then returned to pretreatment values by 24 hour. In a follow-up experiment with ewes, the experimental design was to treat with $4 \mathrm{mg}$ roIFNT per d between d 11 and 15 after onset of estrus and mating; however, this experiment was terminated as too many ewes became sick in response to this treatment regimen (T. E. Spencer and F. W. Bazer, unpublished results).

Recombinant bIFNT may be effective at lower doses than rbIFNA and have fewer undesirable side effects.

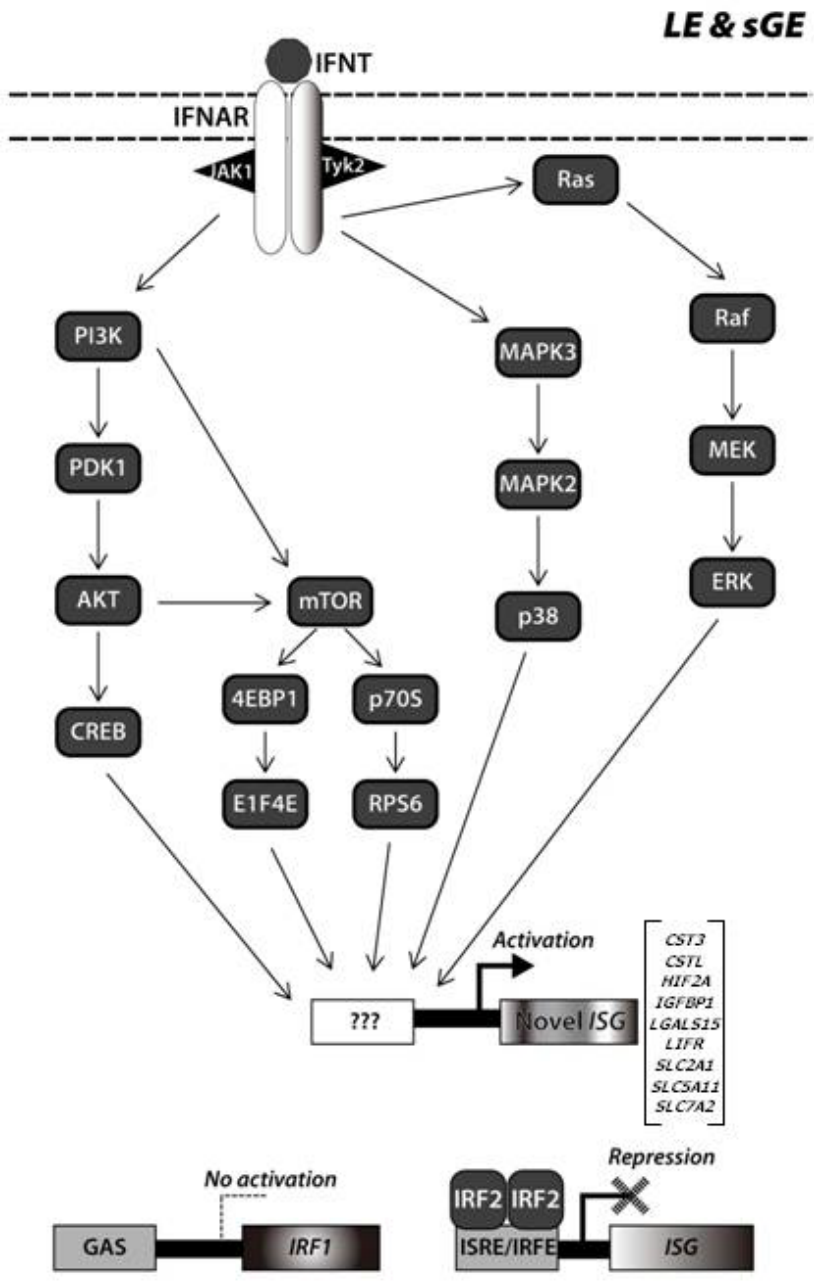

Figure 3. A proposed model of IFNT signal transduction cascades that is independent of STAT1 in the ovine uterine LE and sGE. IFNT-activated JAK1/TYK2 may regulate phosphorylation of PI3K, resulting in downstream activation of PDK1 and AKT. The activated AKT translocates to the nucleus and phosphorylates a variety of target proteins such as $\mathrm{CBP} / \mathrm{p} 300$ or NF- $\mathrm{kB}$. Also, IFNT may activate MAPKKK or Raf which is activated by activated Ras. Activated MAPKKK and/or Raf subsequently regulate activation of downstream effectors including MAPKK, p38 MAPK, or MEK and ERK, respectively. In addition, the mTOR-p70S6K pathway activated by PI3K or AKT, may be involved in mRNA translation of ISGs by phosphorylated RPS6 and translational respressor 4EBP1. Legend: IFNT = Interferon tau; IFNAR = Type I IFN receptor; JAK1 = Janus kinase 1; TYK2 = Tyrosine kinase 2; GAF = Gamma interferon activation factor; GAS = Gamma interferon activation sequence; IRF = Interferon regulatory factor; ISG = Interferon tau-stimulated gene; LGALS15 = Galectin 15; WNT7A = Wingless-type MMTV integration site family, member 7A; CTSL = Cathepsin L; CST3 = Cystatin C; PI3K = Phosphatidylinositol 3-kinase; PDK1 = Phosphoinositide-dependent protein kinase 1; AKT = Proto oncogenic protein kinase Akt; CREB = cAMP-response element binding protein; Mtor = Mechanistic target of rapamycin; 4EBP1 = EIF4-E-binding protein 1; E1F4E = Eukaryotic translation-initiation factor 4 E; p70S = p70 ribosomal protein S6 kinase; RPS6 = Ribosomal protein S6; MAPK3 = Mitogen-activated protein kinase (MAPK) kinase kinase; MAPK $^{2}=$ MAPK kinase; ERK = Extracellular signal-regulated kinase; LE = Luminal epithelium ; Sge = Superficial glandular epithelium (Adapted from Song et al. (2009)). 
Comparing intramuscular injections of 0,1 or $5 \mathrm{mg}$ rbIFNT, the $5 \mathrm{mg}$ dose caused hyperthermia and decreased concentrations of progesterone in plasma (Thatcher et al., 1995). The $1 \mathrm{mg}$ dose of rbIFNT caused a slight rise in rectal temperature, but had no effect on concentrations of P4 in plasma. A continuous release system may be needed for delivery of sufficient rbIFNT to prevent luteolysis without detrimental side effects that reduce embryonic survival in cattle and other ruminant species.

Dietary factors : Linoleic acid is a competitive inhibitor of cyclooxygenase (Thatcher et al., 1995) and levels of nonesterified linoleic acid are greater in endometrial microsomes of pregnant cows on d 17. Since energy and type of dietary fat influence uterine secretion of PGF, research was conducted with tallow and yellow grease which are high in unsaturated fatty acids. Tallow contains little (2\%) linoleic acid and yellow grease is high in linoleic acid (20\%). Following an OXT challenge on d 15 of the estrous cycle, the increase in plasma PGF metabolite (PGFM) was less for cows in which linoleic acid (yellow grease) was infused into the abomasum. For example, cows could be fed ruminal inert polyunsaturated FA of the n-6 (linoleic acid) and n-3[ $\alpha$-linolenic acid; eicosapentaenoic (EPA), C20:5 n-3;docosahexaenoic (DHA), C22:6 n-3] families which are the most beneficial to improving reproduction in cows. Both EPA and DHA are potent inhibitors of PGF synthesis that could exert antiluteolytic and anti-inflammatory effects during early pregnancy. Feeding diets enriched in EPA and DHA (i.e., calcium salts of Fish Oil) during the breeding period of lactating dairy cows increased pregnancy per AI and reduced pregnancy losses (Silvestre et al., 2011).

\section{Placental lactogens in pregnancy}

Ovine IFNT inhibits ESR1 and OXTR gene transcription in endometrial epithelium to abrogate OXT-induced release of luteolytic pulses of PGF and protect CL function (Bazer et al., 2011a). Nevertheless, interestrous intervals are only 30 to $35 \mathrm{~d}$ when conceptuses are flushed from the uterus of ewes on d 16 or after intrauterine infusions of either highly purified native IFNT or recombinant IFNT between d 11 and 15 after onset of estrus. This suggests that a second luteolytic mechanism is activated around $30 \mathrm{~d}$ post-estrus which must be abrogated by the conceptus for maintenance of CL function and pregnancy. We hypothesized that CSH1 was a second "signal" from the conceptus to reinforce antiluteolytic effects of IFNT.

Binucleate cells in trophoblast of sheep conceptuses appear by d 16, migrate into the uterine epithelium and secrete CSH1 (Anthony et al., 1995). Placentae of primate, rodent and ruminant species secrete hormones structurally related to pituitary growth hormone GH1, PRL and CSH1.
Ovine GH1 and CSH1 have similar somatogenic activities, but different patterns of expression during pregnancy. CSH1 is secreted from d 15 to 16 of pregnancy and peak concentrations in maternal blood are between 120 and $130 \mathrm{~d}$ of gestation. CSH1 is lower in fetal serum and peak levels attained at mid-gestation remain stable or decrease to term. Placental GH1 is low in maternal serum except for d 45 to 65 of pregnancy (Lacroix et al., 2002).

There are two human non-allelic growth hormone 1 (GH1) genes (Chen et al., 1989). The maternal pituitary GHN gene is suppressed in the second half of the pregnancy, while placental GHV gene is activated and the placenta becomes the main source of maternal GH, but unlike cattle or swine, sheep have two GH1 genes (Gootwine et al., 1993). Two alleles at the ovine GH locus include the less frequent GH1 allele with a single GH copy and the more frequent GH2 allele that contains two GH copies (GH2N and GH2Z). Thus, GH1/GH1, GH1/GH2 and GH2/GH2 genotypes are present among sheep of different breeds. Sequencing the oGH1 gene $(1.7 \mathrm{~kb})$ revealed that $\mathrm{GH} 2 \mathrm{~N}$ and $\mathrm{GH} 2 \mathrm{Z}$ are almost identical. A variant of the $\mathrm{GH} 2$ allele in which oGHZ, but not oGHN has a Pvu II site in Exon 2 was used to identify a region that encodes for the signal peptide. Using template cDNA from ewe cotyledons and primers that amplify different regions of the GH1 gene, PCR products were identified that correspond to regions in the $G H$ gene. This suggests that $G H 1$ or $G H$-like genes are expressed in the ovine placenta. The bovine placenta also produces CSH1 and proteins of the GH1/PRL gene family (Anthony et al., 1995).

The $22 \mathrm{kDa}$ CSH1 is a non-glycosylated monomer of 198 amino acids that includes three disulfide bonds (Anthony et al., 1995). The cDNA for ovine CSH1 shares nucleotide sequence identity with bovine CSH1 (67\%), ovine PRL (49\%), and mouse CSH1 (31\%), but identity with human CSH1 and ovine and human GH1 is less (25-28\%). CSH1 binds GH1 receptors from pregnant ewe liver and PRL receptors from mammary gland of either pregnant or lactating ewes. There is no evidence for unique CSH1 receptors in endometrium of pregnant cows (Galosy et al., 1991). CSH1 is multifunctional like GH1 and PRL (Talamantes and Ogren, 1988), but CSH1 may be a unique fetal growth hormone (Freemark and Comer, 1989) that stimulates glycogen synthesis, amino acid transport, cellular proliferation and IGF-I synthesis in the fetus. These effects CSH1 are specific since equivalent effects are not induced by either GH1 or PRL. Both ovine and bovine CSH1 can act through PRL receptors in certain species and elicit PRL-like effects in bovine and ovine mammary gland (Shamay et al., 1990). However, CSH1 released into the maternal circulation may influence nutrient partitioning and mammary gland growth and differentiation. 
Uterine secretory responses are affected by P4, E2, PRL and their respective receptor numbers (Chilton and Daniel, 1987). Long-term (12 or more wk) ovariectomized rabbits require treatment with $\mathrm{PRL}$ and then $\mathrm{P} 4$ for secretion of uteroglobin by uterine epithelia. These results led to development of a uterine servomechanism model indicating that PRL binds to its receptor and increases expression of PGR which then allow P4 to stimulate secretion of uteroglobin and PRL also acts to increase numbers of PRL receptors (Chilton et al., 1988). The increase in PRL receptor numbers further increases uterine sensitivity to PRL and amplifies uterine responsiveness to progesterone. CSH1 are not luteotrophic or antiluteolytic when introduced into the uterine lumen or into the maternal circulation in ewes (Spencer et al., 1999). However, CSH1 may influence maintenance of pregnancy in sheep since lactogenic hormones influence steroidogenesis in CL, transport of water by placental membranes, endometrial proliferation, endometrial expression of PGR, protein synthesis and secretion by endometrial epithelium, exocrine secretion of PGF (pigs), and mammary growth and lactation. It is possible that CSH1 from sheep placenta has a role(s) in pregnancy.

Interactions between PRL and P4 increase endometrial proliferation and uteroglobin secretion in long-term ovariectomized rabbits and hyperprolactinemic pigs have more total recoverable uteroferrin, glucose and PGF in uterine flushings (Young et al., 1989). Using a promoterreporter construct and the uteroferrin gene, uteroferrin expression was maximum following sequential exposure of the construct to E2, then PRL and then P4 (Fliss et al., 1991) which confirmed that PRL enhances endometrial secretion of uteroferrin in vivo (Young et al., 1989).

Proteins secreted by uterine GE of ewes during the first $21 \mathrm{~d}$ of gestation have received limited attention; however, total protein and activities of numerous enzymes in uterine secretions are highest during diestrus or in ovariectomized ewes treated with P4 (Ing and Roberts, 1989). The major proteins secreted by uterine GE in ewes are the 57 to 59 $\mathrm{kDa}$ "uterine milk proteins (UTMPs)" or serine protease inhibitors (SERPINS) that have basic isoelectric points and contain high mannose chains that appear to be phosphorylated. The "uterine milk" proteins, like uteroferrin, are secreted in response to long-term treatment of ewes with P4; a protracted effect not typical of a classical steroid-induced secretory responses. The temporal pattern of secretion of SERPINS in uteri of ewes is coordinate with quantitative changes in concentrations of CSH1 in maternal and fetal plasma. This does not prove a cause and effect relationship, but interactions between $\mathrm{P} 4$ and $\mathrm{CSH} 1$ to stimulate secretion of SERPINS is consistent with the servomechanism concept developed in studies with rabbits.

A hormonal servomechanism has been proposed to regulate differentiation and function of ovine uterine GE during pregnancy. This mechanism involves sequential actions of E2, P4, IFNT, CSH1 and GH1 with biological actions of $\mathrm{CSH} 1$ being mediated by homodimerization of the PRLR or heterodimerization of the PRLR and GH1 receptor (Noel et al., 2003). Endometrial expression of ESR1, PGR and OXTR is not affected by either CSH1 or GH1; however, expression of serine protease inhibitor, kunitz-type, 1 (SPINT1) by uterine GE increases in response to both $\mathrm{CSH} 1$ and $\mathrm{GH}$, but only if ewes are first treated with intra-uterine IFNT between d 11 and 21, and then CSH1 or GH and P4 daily from d 16 to 29 after onset of estrus (Bazer et al., 2009). Only CSH1 stimulated expression of both UTMP and SPP1 in uterine GE. Downregulation of epithelial PGR expression is also required for P4 induction of SPP1 and SPINT1 gene expression by uterine GE with effects of P4 presumably being mediated by a progestamedin from stromal cells such as FGF10. Ewes treated with both P4 and E2 experienced an increase in PGR in GE which suppressed expression of both SPP1 and SPINT1 (Spencer et al., 1999). The mechanism whereby IFNT permits GE to become responsive to CSH1 and $\mathrm{GH}$ is not known.

\section{Common signaling mechanisms for regulation of endometrial gene transcription by IFNT and CSH1 (Yu- Lee et al., 1990; Darnell et al., 1994)}

Prolactin signals cells through JAK2 while Type I IFNs signal through JAK1 and tyrosine kinase 2 (TYK2). Type I IFNs induce formation of ISGF3 which complexes with a $48 \mathrm{kDa}$ DNA binding protein and binds to ISREs. Formation of the ISGF3 complex and its migration to the nucleus requires tyrosine phosphorylation of STAT1 and STAT2 proteins by JAK1. At present, transcriptional signal(s) have not been fully elucidated for the PRLR. However, common signaling pathways for PRL and Type I IFNs suggest similar mechanisms for maintaining uterine responsiveness to $\mathrm{P} 4$ during pregnancy.

\section{Luteotrophic hormones}

Cattle : In cows, LH alone is sufficient to support CL function during gestation. However, pregnancy can be maintained in hypophyseal stalk-transectioned cows suggesting that a fetal-placental hormone(s) may influence maintenance of pregnancy.

Sheep : Ewes require LH and/or PRL for maintenance of pregnancy until about d 60 when the conceptus assumes responsibility for CL maintenance and production of adequate P4 to support pregnancy. Neither hypophysectomy of the fetus nor ovariectomy of the ewe after $d 60$ of gestation results in abortion which indicates that the fetalplacental unit is autonomous after that time. 


\section{ACKNOWLEDGEMENTS}

This research was funded by the World Class University (WCU) program (R31-10056) funded by the Ministry of Education, Science, and Technology, Republic of Korea (GS, FWB), as well as National Research Initiative Competitive Grant no. 2006-35203-17283 from the USDA National Institute of Food and Agriculture.

\section{REFERENCES}

Anthony, R. V., S. L. Pratt, R. Liang and M. D. Holland. 1995. Placental-fetal hormonal interactions: Impact on fetal growth. J. Anim. Sci. 73:1861-1871.

Ashworth, C. J. and F. W. Bazer. 1989. Interrelationships of proteins secreted by the ovine conceptus and endometrium during the preiattachment period. Anim. Reprod. Sci. 20:117130.

Barros, C. M., J. G. Betts, W. W. Thatcher and P. J. Hansen. 1992. Possible mechanisms for reduction of circulating concentrations of progesterone by interferon- $\alpha$ in cows: Effects on hyperthermia, luteal cells, metabolism of progesterone and secretion of LH. J. Endocrinol. 133:175-182.

Bazer, F. W. and N. L. First. 1983. Pregnancy and parturition. J. Anim. Sci. 57(Suppl. 2):425-458.

Bazer, F. W., T. L. Ott and T. E. Spencer. 1994. Pregnancy recognition in ruminants, pigs and horses: signals from the trophoblast. Theriogenology 41:79-94.

Bazer, F. W., T. E. Spencer and G. A. Johnson. 2009. Interferons and uterine receptivity. Semin. Reprod. Med. 27:90-102.

Bazer, F. W., G. Wu, T. E. Spencer, G. A. Johnson, R. C. Burghardt and K. Bayless. 2010. Novel pathways for implantation and establishment and maintenance of pregnancy in mammals. Mol. Hum. Reprod. 16:135-152.

Bazer, F. W., T. E. Spencer, G. A. Johnson and R. C. Burghardt. 2011a. Uterine receptivity to implantation of blastocysts in mammals. Front. Biosci. S3:745-767.

Bazer, F. W., G. Wu, G. A. Johnson, J. Kim and G. Song. 2011b. Uterine histotroph and conceptus development: Select nutrients and secreted phosphoprotein 1 affect MTOR cell signaling in ewes. Biol. Reprod. Aug 24. (Epub ahead of print).

Bott, R. C., R. L. Ashley, L. E. Henkes, A. Q. Antoniazzi, J. E. Bruemmer, G. D. Niswender, F. W. Bazer, T. E. Spencer, N. P. Smirnova, R. V. Anthony and T. R. Hansen. 2010. Uterine vein infusion of interferon tau (IFNT) extends luteal life span in ewes. Biol. Reprod. 82:725-735.

Carson, D. D., E. Lagow, A. Thathiah, R. Al-Shami, M. C. FarachCarson, M. Vernon, L. Yuan, M. A. Fritz and B. Lessey. 2002. Changes in gene expression during the early to mid-luteal (receptive phase) transition in human endometrium detected by high-density microarray screening. Mol. Hum. Reprod. 8:871879.

Chami, O., A. Megevand, T. L. Ott, F. W. Bazer and C. O’Neill. 1999. A role for platelet-activating factor as an endogenous pulse-generator for the release of luteolytic PGF from the ovine endometrium. Am. J. Physiol. 276:E783-E792.

Charleston, B. and H. J. Stewart. 1993. An interferon-induced Mx protein: cDNA sequence and high level expression in the endometrium of pregnant sheep. Gene 137:327-331.

Chen, C., T. E. Spencer and F. W. Bazer. 2000a. Fibroblast growth factor-10: A stromal mediator of epithelial function in the ovine uterus. Biol. Reprod. 63:959-966.

Chen, C., T. E. Spencer and F. W. Bazer. 2000b. Expression of hepatocyte growth factor and its receptor c-met in the ovine uterus. Biol. Reprod. 62:1844-1850.

Chen, E. Y., Y. C. Liao, D. H. Smith, H. A. Barrera-Saldana, R. E. Gelinas and P. H. Seeburg. 1989. The human growth hormone locus nucleotide sequence, biology and evolution. Genomics 4:479-497.

Chilton, B. S. and J. C. Daniel. 1987. Differences in the rabbit uterine response to progesterone as influenced by growth hormone or prolactin. J. Reprod. Fertil. 79:581-587.

Chilton, B. S., S. K. Mani and D. W. Bullock. 1988. Servomechanism of prolactin and progesterone in regulating uterine gene expression. Mol. Cell. Endocrinol. 2:1169-1175.

Cooke, F. N., K. A. Pennington, Q. Yang and A. D. Ealy. 2009. Several fibroblast growth factors are expressed during preattachment bovine conceptus development and regulate interferon-tau expression from trophectoderm. Reproduction 137:259-269.

Danet-Desnoyers, G., C. Wetzels and W. W. Thatcher. 1994. Natural and recombinant bovine interferon tau regulate basal and oxytocin-induced secretion of prostaglandins F2 alpha and E2 by epithelial cells and stromal cells in the endometrium. Reprod. Fertil. Dev. 6:193-202.

Darnell, J. E. Jr., I. M. Kerr and G. R. Stark. 1994. Jak-STAT pathways and transcriptional activation in response to IFNs and other extracellular signaling proteins. Sciences 264:14151421.

Davis, M. A., T. L. Ott, M. A. Mirando, M. T. Moser and F. W. Bazer. 1992. Effect of recombinant alpha interferons on fertility and interstrous interval in sheep. Theriogenology 38:867-875.

Dorniak, P., F. W. Bazer and T. E. Spencer. 2011. Prostaglandins regulate conceptus elongation and mediate effects of interferon tau on the ovine uterine endometrium. Biol. Reprod. 84:11191127.

Drost, M., J. M. Wright and R. P. Elsden. 1986. Intergeneric embryo transfer between water buffalo and domestic cattle. Theriogenology 25:13-23.

Eley, R. M., W. W. Thatcher, F. W. Bazer and M. J. Fields. 1983. Steroid metabolism by the bovine uterine endometrium and conceptus. Biol. Reprod. 28:804-816.

Fincher, K. B., F. W. Bazer, P. J. Hansen, W. W. Thatcher and R. M. Roberts. 1986. Proteins secreted by the sheep conceptus suppress induction of uterine prostaglandin F2a release by estradiol and oxytocin. J. Reprod. Fertil. 76:425-433.

Fleming, J. G. W., T. E. Spencer, S. H. Safe and F. W. Bazer. 2006. The ovine uterine oxytocin receptor gene: Regulation of expression by estradiol and role of IFNT signaling for establishment of pregnancy in ruminants. Endocrinology 147:899-911.

Fliss, A. E., F. J. Michel, C. L. Chen, F. W. Hofig, J. Y. Chou and R. C. M. Simmen. 1991. Regulation of the uteroferrin gene promoter in endometrial cells: Interactions between estrogen, progesterone and prolactin. Endocrinology 129:697-704.

Freemark, M. and M. Comer. 1989. Purification of a distinct 
placental lactogen receptor, a new member of the growth hormone/prolactin family. J. Clin. Invest. 83:883-889.

Galosy, S., A. Gertler, G. Elberg and D. Laird. 1991. Distinct placental lactogen and prolactin (lactogen) receptors in bovine endometrium. Mol. Cell. Endocrinol. 78:229-236.

Gootwine, E., J. A. Sise, J. M. Penty and G. W. Montgomery. 1993. The duplicated gene copy of the ovine growth hormone gene contain a Pvu II polymorphism in the second intron. Anim. Genet. 24:319-321.

Guillomot, M. 1995. Cellular interactions during implantation in domestic ruminants. J. Reprod. Fertil. Suppl. 49:39-51.

Han, H., K. J. Austin, L. A. Rempel and T. R. Hansen. 2006. Low blood ISG15 mRNA and progesterone levels are predictive of non-pregnant dairy cows. J. Endocrinol. 191:505-512.

Helmer, S. D., T. S. Gross, G. R. Newton, P. J. Hansen and W. W. Thatcher. 1989. Bovine trophoblast protein-1 complex alters endometrial protein and prostaglandin secretion and induces an intracellular inhibitor of prostaglandin synthesis in vitro. J. Reprod. Fertil. 87:421-430.

Hernandez-Ledezma, J. J., J. D. Sikes, C. N. Murphy, A. J. Watson, G. A. Schultz and R. M. Roberts. 1992. Expression of bovine trophoblast interferon in conceptuses derived by in vitro techniques. Biol. Reprod. 47:374-380.

Imakawa, K., S. D. Helmer, K. P. Nephew, C. S. R. Meka and R. K. Christenson. 1993. A novel role for GM-CSF: Enhancement of pregnancy specific interferon production, ovine trophoblast protein-1. Endocrinology 132:1869-1871.

Ismail, S. T. 1987. Reproduction in the female camel (Camelus dromedarius). Theriogenology 28:363-371.

Ing, N. H. and R. M. Roberts. 1989. The major progesteronemodulated proteins secreted into the sheep uterus are members of the serpin superfamily of serine protease inhibitors. J. Biol. Chem. 264:3372-3379.

Kim, J., R. C. Burghardt, G. Wu, G. A. Johnson, T. E. Spencer and F. W. Bazer. 2011a. Select Nutrients in the ovine uterine lumen: VII. Effects of arginine, leucine, glutamine and glucose on trophectodem cell signaling, proliferation and migration. Biol. Reprod. 84:70-78.

Kim, J., R. C. Burghardt, G. Wu, G. A. Johnson, T. E. Spencer and F. W. Bazer. 2011b. Select Nutrients in the ovine uterine lumen: VIII. Arginine stimulates proliferation of ovine trophectoderm cells through mTOR-RPS6K-RPS6 signaling cascade and synthesis of nitric oxide and polyamines. Biol. Reprod. 84:62-69.

Knickerbocker, J. J., W. W. Thatcher, F. W. Bazer, M. Drost, D. H. Barron, K. B. Fincher and R. M. Roberts. 1986a. Proteins secreted by day-16 to -18 bovine conceptuses extend corpus luteum function in cows. J. Reprod. Fertil. 77:381-391.

Knickerbocker, J. J., W. W. Thatcher, F. W. Bazer, D. H. Barron and R. M. Roberts. 1986b. Inhibition of uterine prostaglandinF2 alpha production by bovine conceptus secretory proteins. Prostaglandins 31:777-793.

Lacroix, M. C., J. Guibourdenche, J. L. Frendo, G. Pidoux and D. Evain-Brion. 2002. Placental growth hormones. Endocrine 19:73-79.

Lee, J. S. and W. J. Silvia. 1994. Cellular mechanisms mediating the stimulation of ovine endometrial secretion of prostaglandin $F_{2 \alpha}$ in response to oxytocin: role of phospholipase $A_{2}$. J. Endocrinol. 141:491-496.
Loureiro, B., J. Block, M. G. Favoreto, S. Carambula, K. A. Pennington, A. D. Ealy and P. J. Hansen. 2011. Consequences of conceptus exposure to colony-stimulating factor 2 on survival, elongation, interferon- $\tau$ secretion, and gene expression. Reproduction 141:617-624.

McCracken, J. A., W. Schramm and W. C. Okulicz. 1984. Hormone receptor control of pulsatile secretion of $\mathrm{PGF}_{2 \alpha}$ from ovine uterus during luteolysis and its abrogation in early pregnancy. Anim. Reprod. Sci. 7:31-56.

McCracken, J. A., E. E. Custer and J. C. Lamsa. 1999. Luteolysis: A neuroendocrine-mediated event. Physiol. Rev. 79:263-323.

Meyer, M. D., M. Drost, T. L. Ott, F. W. Bazer, L. Badinga, J. Li, R. M. Roberts, P. J. Hansen and W. W. Thatcher. 1995. Recombinant bovine and ovine interferon tau extend CL lifespan and reduce uterine secretion of prostaglandin $F_{2 \alpha}$ in cattle. J. Dairy Sci. 78:1921-1931.

Mishra, D. P., H. H. Meyer and B. S. Prakash. 2003. Validation of a sensitive enzyme immunoassay for 13,14-dihydro-15-ketoPGF2 alpha in buffalo plasma and its application for reproductive health status monitoring. Anim. Reprod. Sci. 15:78:33-46.

Morton, H. 1985. EPF as a pregnancy protein. In: Early Pregnancy Factor (Ed. F. Ellendorf and E. Koch). Perinatology Press, Ithaca, New York, pp. 53-64.

Nephew, K. P., K. E. McClure, M. L. Day, S. Xie, R. M. Roberts and W. F. Pope. 1990. Effects of intramuscular administration of recombinant bovine interferon-alpha 1 during the period of maternal recognition of pregnancy. J. Anim. Sci. 68:2766-2770.

Noel, S., A. Herman, C. A. Johnson, C. A. Gray, M. D. Stewart, F. W. Bazer, A. Gertler and T. E. Spencer. 2003. Ovine placental lactogen specifically binds to endometrial glands of the ovine uterus. Biol. Reprod. 68:772-780.

O'Neill, C., X. Wells and K. Battye. 1990. Embryo-derived platelet activating factor: Interactions with the arachidonic acid cascade and the establishment and maintenance of pregnancy. Reprod. Fertil. Dev. 2:423-441.

Ott, T. L., A. A. Wiley, T. E. Spencer, F. F. Bartol and F. W. Bazer. 1995. Uterine expression of interferon-induced $\mathrm{Mx}$ in cyclic and pregnant ewes. Biol. Reprod. 52 (Suppl 1):143(Abstr.).

Ott, T. L., J. C. W. Fleming, T. E Spencer, M. M. Joyce, P. Chen, C. N. K. Green, D. Zhu, T. H. Welsh, P. G. Harms and F. W. Bazer. 1997. Effect of exogenous recombinant ovine interferon tau on circulating concentrations of progesterone, cortisol, LH and antiviral activity, interestrous interval, rectal temperature, and uterine response to oxytocin in cyclic ewes. Biol. Reprod. 57:621-629.

Platanias, L. C. 2005. Mechanisms of type-I- and type-IIinterferon-mediated signaling. Nat. Rev. Immunol. 5:375-386.

Roberts, R. M., J. C. Cross and D. W. Leaman. 1992. Interferons as hormones of pregnancy. Endocrine Rev. 13:432-452.

Robinson, S. J., H. Neal and W. R. Allen. 2000. Modulation of oviductal transport in mares by local application of prostaglandin E2. J. Reprod. Fertil. (Suppl 56):587-592.

Rueda, B. R., K. A. Naivar, E. M. George, K. J. Austin, H. Francis and T. R. Hansen. 1993. Recombinant interferon- $\tau$ regulates secretion of two bovine endometrial proteins. J. Interferon Res. 13:295-301.

Satterfield, M. C., K. Hayashi, G. Song, S. G. Black, F. W. Bazer and T. E. Spencer. 2008. Progesterone regulates FGF10, MET, 
IGFBP1, and IGFBP3 in the endometrium of the ovine uterus. Biol. Reprod. 79:1226-1236.

Schmitt, R. A., R. D. Geisert, M. T. Zavy, E. C. Short and R. M. Blair. 1993. Uterine cellular changes in 2',5'-oligoadenylate synthetase during the bovine estrous cycle and early pregnancy. Biol. Reprod. 48:460-466.

Shamay, A., M. Pines, M. Waksman and A. Gertler. 1990. Proliferation of bovine mammary epithelial cells in vitro is modulated by G-proteins. Mol. Cell. Endocrinol. 69:217-226.

Short, E. C., R. D. Geisert, S. D. Helmer, M. T. Zavy and R. W. Fulton. 1991. Expression of antiviral activity and induction of 2,5' oligoadenylate synthetase by conceptus secretory proteins enriched in bovine trophoblast protein-1. Biol. Reprod. 44:261-268.

Silvestre, F. T., T. S. M. Carvalho, N. Francisco, J. E. P. Santos, C. R. Staples, T. C. Jenkins and W. W. Thatcher. 2011. Effects of differential supplementation of fatty acids during the peripartum and breeding periods of Holstein cows: I. Uterine and metabolic responses, reproduction and lactation. J. Dairy Sci. 94:189-204.

Silvia, W. J. and R. E. Raw. 1993. Activity of phospholipase C and release of prostaglandin $F_{2 \alpha}$ by endometrial tissue from ewes during the oestrous cycle and early pregnancy. J. Reprod. Fertil. 97:529-537.

Simmons, R. M., M. C. Satterfield, T. H. Welsh, F. W. Bazer and T. E. Spencer. 2010. HSD11B1, HSD11B2, PTGS2 and NR3C1expression in the peri-implantation ovine uterus: effects of pregnancy,progesterone and interferon tau. Biol. Reprod. 82:35-43.

Song, G., J. Y. Han, T. E. Spencer and F. W. Bazer. 2009. Interferon tau in the ovine uterus. J. Anim. Sci. Technol. 51:471-484.

Spencer, T. E. and F. W. Bazer. 1995a. Temporal and spatial alterations in uterine estrogen receptor and progesterone receptor gene expression during the estrous cycle and early pregnancy in the ewe. Biol. Reprod. 53:1527-1545.

Spencer, T. E., M. A. Mirando, T. F. Ogle and F. W. Bazer. 1995b. Ovine interferon- $\tau$ inhibits estrogen receptor up-regulation and estrogen-induced luteolysis in cyclic ewes. Endocrinology 136:4932-4944.
Spencer, T. E., T. L. Ott, A. Gertler, E. Gootwine and F. W. Bazer. 1999. Effects of recombinant ovine interferon tau, placental lactogen and growth hormone on the ovine uterus. Biol. Reprod. 61:1409-1418.

Talamanates, F. and L.Ogren. 1988. The placenta as an endocrine organ. In: The Physiology of Reproduction: Polypeptides (Ed. E. Knobil and J. Neill), Raven Press Ltd, New York, pp. 2093-2144.

Tamby, J. P., G. Charpigny, P. Reinaud and J. Martal. 1993. Phospholipase A2 activity in endometrium from early pregnant and non-pregnant ewes. Prostaglandins 46:407-415.

Thatcher, W. W., M. D. Meyer and G. Danet-Desnoyers. 1995. Maternal recognition of pregnancy. J. Reprod. Fertil. (Suppl 49):15-28.

Thatcher, W. W., C. R. Staples, G. Danet-Desnoyers, B. Oldick and E. P. Schmitt. 1994. Embryo health and mortality in sheep and cattle. J. Anim. Sci. 72(Suppl. 3):16-30.

Vallet, J. L., P. J. Barker, G. E. Lamming, N. Skinner and N. S. Huskisson. 1991. A low molecular weight endometrial secretory protein which is increased by ovine trophoblast protein-1 is a beta 2-microglobulin-like protein. J. Endocrinol. 130:R1-R4.

Weber, J. A., D. A. Freeman, D. K. Vanderwall and G. L. Woods. 1991. Prostaglandin E2 hastens oviductal transport of equine embryos. Biol. Reprod. 45:544-546.

Xavier, F., M. Guillomot, M. Charlier, J. Martal and P. Gaye. 1991. Co-expression of the protooncogene FOS (cfos) and an embryonic interferon (ovine trophoblastin) by sheep conceptuses during implantation. Biol. Cell 73:27-33.

Yankey, S. J., B. A. Hicks, K. G. Carnahan, A. M. Assiri, S. J. Sinor, K. Kodali, J. N. Stellflug and T. L. Ott. 2001. Expression of the antiviral protein $\mathrm{Mx}$ in peripheral blood mononuclear cells of pregnant and bred, non-pregnant ewes. J. Endocrinol. 170:R7-R11.

Young, K. H., R. R. Kraeling and F. W. Bazer. 1989. Effects of prolactin on conceptus survival land uterine secretory activity in pigs. J. Reprod. Fertil. 86:713-722.

Yu-Lee, L. Y., J. A. Hrachovy, A. M. Stevens and L. A. Schwarz. 1990. Interferon regulatory factor 1 is an immediate-early gene under transcriptional regulation by prolactin in $\mathrm{Nb} 2 \mathrm{~T}$ cells. Mol. Cell. Biol. 10:3087-3094. 